\title{
Genomic Analysis of Rotavirus Species A Isolated from Swine, Amazon Region, Brazil
}

\author{
Mayara A.O. Neves ${ }^{1}$, Daniel S. De Camargo ${ }^{2}$, Kathleen V.S. de Araújo ${ }^{3}$, \\ Patrícia S. Lobo ${ }^{3}$, Renato Da S. Bandeira ${ }^{1}$, Luana S. Soares ${ }^{3}$ and \\ Joana D.P. Mascarenhas ${ }^{3 *}$
}

${ }^{1}$ Postgraduate Program in Virology, Evandro Chagas Institute, Ananindeua, Pará, Brazil

${ }^{2}$ Center for Tropical Medicine, Federal University of Pará, Pará, Brazil

${ }^{3}$ Virology Section, Evandro Chagas Institute, Health Surveillance Secretariat, Brazilian

Ministry of Health, Ananindeua, Pará, Brazil

*Corresponding author

\section{A B S T R A C T}

This present study has aimed to provide a molecular characterization of rotavirus species A (RVA) and to determine the frequency of RVC and RVH in fecal specimens from non-

\section{Keywords}

Porcine, Zoonotic potential, Rotavirus A, Phylogenetic analysis,

Environmental microbiology

\section{Article Info}

Accepted: 07 October 2018 Available Online: 10 November 2018 vaccinated piglets, across 5 farms in the metropolitan mesoregion of Belém, within the Amazon region, Brazil. In the previous study, porcine RVA was found in $9.9 \%(17 / 172)$ during the years 2008-2009. Using RT-PCR, Sanger nucleotide sequencing, and phylogenetic analyses, the entire genomes of 17 Brazilian porcine RVA strains were analyzed. The results indicated that all strains shared the same constellation, with the exception of the VP3 and NSP3 genes, which were M2 and T7 genotypes, respectively. The VP1, VP2, NSP2, NSP4 and NSP5 coding segments clustered into the Wa-like constellation; genotype 1, and VP7, VP4, VP6 and NSP1 genes were typically of porcine origin. RVA genes infecting pigs presented a high degree of nucleotide similarity to strains from other hosts, including humans. Little is known about the zoonotic potential of rotaviruses in Brazil, but the results of this study show dynamic interactions between human and porcine rotavirus strains and constitute an increase in knowledge on the diversity of RVA strains, in animal reservoirs circulating in the Amazon region.

\section{Introduction}

Several viral agents can cause diarrhea in developing pigs, among which are rotaviruses (RVs). RVs are the leading cause of serious diarrhea dehydration in children and animals worldwide, including piglets in the pre- and post- weaning stages (Lanata et al., 2013; Chang, Kim, Saif, 2012). RVs belong to the Reoviridae family, and possess a genome composed of approximately $18,500 \mathrm{bp}$, consisting of 11 double-stranded RNA segments inserted into the viral core, which encodes six structural proteins (VP1-VP4, VP6 and VP7) and six non-structural proteins (NSP1 -NSP5 / 6) (Vlasova, Amimo, Saif, 2017). RVs are classified into nine groups/species (RVA-RVI), and more recently a new species (RVJ) has been proposed based on the antigenic properties of the VP6 protein 
(ICTV, 2017; Mihalov-Kovacs et al., 2015; Bányai et al., 2017). Of these, RVA, RVB, $\mathrm{RVC}, \mathrm{RVE}$ and RVH have been described in swine (Alfieri et al., 1999; Molinari et al., 2015; Wakuda et al., 2011). Several studies provide evidence that RVA present in pigs, due to a high genetic variability in the antigenic regions, is able to cross the barrier between species, causing diarrhea in humans and other domesticated animals, and vice versa, reinforcing the existence of an evolutionary relationship (Martella et al., 2010; Theuns et al., 2015; Papp et al., 2013). In order to better understand the relationship between RVA strains in different host species, Matthijnssens et al., (2011) proposed a new genomic classification, based on the molecular characteristics of the genes VP7- VP4- VP6VP1- VP2- VP3- NSP1- NSP2-NSP3- NSP4and NSP5/6, designating different genotypes Gx-P[x]-Ix-Rx-Cx-Mx-Ax-Nx-Tx-Ex-Hx, respectively, where " $\mathrm{x}$ " defines the genotypes of the proteins. Epidemiological surveillance studies show that porcine RVA strains exhibit a combination of G2-G5, G9 and G11 genotypes with P[6], P[7], P[13], P[19], P[23], $\mathrm{P}[26]$ and $\mathrm{P}[27]$, respectively, and are typically expressed in the I5/I12-R1-C1-M1A8-N1-T1/T7-E1-H1 backbone (Martella et al., 2010; Silva et al., 2015; Okitsu et al., 2013).

In Brazil, most of the studies on RVAaffecting swine occurred in the South and Southeast of the country, due to their high pork production level, these regions containing an important portion $(85 \%)$ of the country's pig population (IBGE, 2016). However, in the Amazon region, located in northern Brazil, there is still only limited data on the genetic diversity of RVA strains circulating in swine, despite the importance of these animals as reservoirs for the genetic diversity of the virus. Camargo et al., (2012) identified RVA as an important agent for causing diarrhea in pigs inside the region, at a frequency of $9.9 \%$, with the first registration of the G3P[23] genotype in Brazil. However, none of these porcine RVA strains was molecularly characterized in its complete genome (Camargo et al., 2012). The present study aimed to characterize all the genes of porcine RVA, in addition to describing the frequency of RVC and RVH in samples from pig farms in the metropolitan mesoregion of Belém, located in the North region of Brazil; to our knowledge this manuscript is the first to report the sequences of all RVA genes affecting swine in the Amazon region, including a description of the M2 genotype in the country.

\section{Materials and Methods}

\section{Fecal specimens}

Samples were collected from April 2008 to May 2009, from non-vaccinated pigs during the pre-weaning and post-weaning phases, from five pig farms, these being of commercial and medium sizes. These samples were previously described in the Camargo et al., (2012) study, which described 9.9\% (17/172) as being positive for RVA, with partial characterization of the VP7 and VP4 genes, respectively obtaining 70.6\% (12/17) and $23.5 \%$ (4/17) G and P genotypes.

\section{RVA detection and RT-PCR}

The viral genome was extracted from $10 \%$ fecal suspensions through the technique described by Boom et al., (1990). All RVA positive samples were submitted to a reverse transcription polymerase chain reaction (RTPCR), using a panel of primers previously described by Gouvea et al., (1990), Gentsch et al., (1992) Varghese et al., (2006), Matthijnssens et al., (2006), (2008), Barbosa et al., (2013) Silva et al., (2014) and Cunliffe et al., (1997), aiming to partially amplify the eleven RVA genes. 


\section{RVC and RVH detection}

Subsequent to extracting the viral genome from all samples collected $(n=172), \mathrm{RVC}$ and RVH were also investigated by RT-qPCR and RT-PCR respectively. To detect RVC, the primers and the hydrolysis probes selected for the study were based on the study by Marthaler et al., (2014). While for the characterization of the RVH VP6 gene, the technique was performed according to the model outlined by Molinari et al., (2014).

\section{Nucleotide Sequencing}

The RVA-positive samples were sequenced from the eleven rotavirus genes, using the same primers used in RT-PCR and performed according to the protocol described by the manufacturer of the Big Dye Terminator kit (Applied Biosystems, Foster City, CA). Electrophoresis was carried out on the ABI Prism 3130xl automatic sequencer (Applied Biosystems) according to Sanger et al., (1977).

\section{Bioinformatics Analysis}

Assembly for the partial sequences obtained was undertaken in the Geneious 10.0.6 program (Kearse et al., 2012), and alignment was made in the Aliview v.3.0 (Larsson, 2010) and Mafft v.7.221 programs (Katoh; Toh, 2013). All samples were characterized by a phylogenetic analysis using prototypes deposited at Genbank using the BLAST tool. For the Maxima-Likelihood analysis, the IQTree v.1.3.0 program (Nguyen et al., 2015) was used by the Ultrafast Bootstrap (UFboot) method (Minh et al., 2013) with 1000 bootstrap replicas. The nucleotide similarity was calculated in MEGA 6.0 (Tamura et al., 2013). The sample access numbers are:VP7 MH785304-MH785320; VP4 MH785321MH785336; VP6 MH785337- MH785350; VP1 MH785351-MH785367; VP2
MH785368-MH785384; VP3 MH785385MH785396; NSP1 MH785397-MH785410; NSP2 MH785411-MH785425; NSP3 MH785426 -MH785440; NSP4 MH785441MH785457; NSP5 MH785458-MH785474.

\section{Ethics}

This study was approved by the Ethics Committee for the Use of Animals, of the EvandroChagas Institute, under copy number $10 / 2016$.

\section{Results and Discussion}

Previously, Camargo et al., (2012) described the genotypes G3, G5 and P[23] in 53\% (9/17), $17 \%(3 / 17)$ and $23 \%(4 / 17)$ of the samples respectively, and the G3P[23] combination was detected in $23 \%$ (4/17) of specimens.

In this analysis it was possible to describe the binary combination of other samples, where the following types were observed: G3P[13] $(35 \%, 6 / 17)$, G5P[13] (29\%, 5/17), and G3P[23] $(6 \%, 5 / 17)$; only in one specimen was the combination not obtained, namely in $\mathrm{G} 3 \mathrm{P}[\mathrm{x}](6 \%, 1 / 17)$.

With respect to the genetic constellation, the following types were observed: G3/G5P[13]/P[23]-I5-R1-C1-M1/M2-A8-N1-T1/T7E1-H1. All strains shared the same constellation with the exception of the VP3 and NSP3 genes.

The VP1, VP2, NSP2, NSP4 and NSP5 coding segments clustered into the Wa-like constellation, genotype 1; and VP7, VP4, VP6 and NSP1 genes were typically of porcine origin. The genotype constellations for the porcine RVA samples are shown in Table 1. $\mathrm{RVC}$ findings in the swine samples presented a positivity of $1.2 \%$ (2/172), while RVH was not identified (data not shown). 


\section{Phylogenetic analysis of genes encoding} structural proteins

In the construction of the VP7 gene's phylogenetic tree, the most frequent genotype was G3, which corresponded to $71 \%$ (12/17) of the isolates, these grouping into a single clade. They presented $100 \%$ similarity to each other, and a higher nucleotide identity with strains from an Asian swine origin that circulated in Thailand, China and Japan, as well as in Chile. With respect to the G5 genotype, it was detected in $29 \%$ of the samples (5/17), presenting a high similarity (>93\%) with strains of human origin, isolated in Brazil in 1986 and 1988 (mg28018, sp30846, rj36700 and IAL-R3029), and one of 97\% with a strain of bovine origin (IAL28xUK) (Figure 1). Phylogenetic analysis of the VP4 gene showed that the P[13] genotype was identified in 69\% (11/16) of the findings and was phylogenetically related to strains from pigs that clustered in the P[13].1 clade, and were more closely related (85\%) to other pig isolates in Japan in 2002 and 2008 (JP35-7 and JP91-K2), and in Ireland (2B) in 2005. Phylogenetic analysis allowed the identification of four clades.

The first one (P[13].1) included all Brazilian strains in this study isolated in 2008, and three strains of pigs collected in Japan (JP357/JP91-K26) and Ireland (2B), which were classified as $\mathrm{P}[13] /[22]$; the second cluster (P[13].2) contained only $\mathrm{P}[13]$ sequences from rabbits (previously classified as $\mathrm{P}$ [22]): (160/01, 229/01, 308/01, 3989/3); the third cluster (P[13].3) was composed of strains isolated from animals: five from pigs (CMP29/08, 2-3, CMP213, HP113, ROTA09) and one from wild boars (P245) collected between 2002 and 2015; the fourth cluster (P[13].4) was represented by an Australian pig strain (MDR-13), a prototype of the P[13] genotype (Figure 2). The P[23] genotype of the Brazilian strains in this study was the first record associated with infection in swine within the country. The $\mathrm{P}[23]$ genotype grouped phylogenetically distant strains $(83 \%)$ from other $\mathrm{P}[23]$ strains of swine circulating in Brazil (PGRV13), Italy (3BS, 7RE) and a number of Asian countries (NMLT, 3-17, CMP48/08, and CMP45/08). Conversely, the Thai P[23] strain (KKL-117) of human RVA had a higher nucleotide identity $(91 \%)$ with the $\mathrm{P}[23]$ sample circulating in pigs from the present study (Figure 2). In analysis of the VP6 gene, all the samples were pooled into the I5 genotypes that are commonly associated with pig RVA. The phylogenetic tree showed a high genotype heterogeneity for I5 in the Brazilian strains, since these formed three distinct groups: two groups of Brazilian I5 strains almost exclusively contained strains of porcine RVA (91-92\%), and the other group chiefly contained swine strains, as well as strains from humans, wild boars and simians (92-93\%) (Figure 3). Phylogenetic analysis of the VP1 gene's ORF partial sequences, R1 genotype, showed a $100 \%$ similarity between them and a close phylogenetic relationship (94\%) with strains that are related to pigs from four continents: America, Europe, Asia and Africa (Figure 4). However, and interestingly, for the VP2 gene of genotype C1, Brazilian strains formed two clusters, revealing a high nucleotide similarity (93-94\%) with equine (H-1), bovine (KJ56-1), human (kkl-117, 0796s1118, 104-701-D152, 14250_9) and swine strains (3-18, 2-3, ROTA09, 7RE, OSU-C511, 174-1, LS00006OSU) (Figure 5). Similarly to the VP2 gene analysis, the partial sequence of the VP3 gene (M1 genotype) also demonstrated a high nucleotide similarity (9395\%) with the bovine (K5), human (KisB332), equine (H-1) and porcine (OSU-C5111, LS00006OSU, 7RE, ET8B). On the other hand, the M2 genotype grouped more closely (97\%) with a strain that recently circulated in humans in the North of Brazil, specifically in 2016 (AM-16-67). 
Fig.1 Phylogenetic analyze of VP7 protein of circulating porcine Brazilian RVA strains. The level of bootstrap support is indicated at each node (values $<70 \%$ were omitted). The circle represents the strains of this study. (*) indicates the strains identified in the Camargo, et al., (2012) study

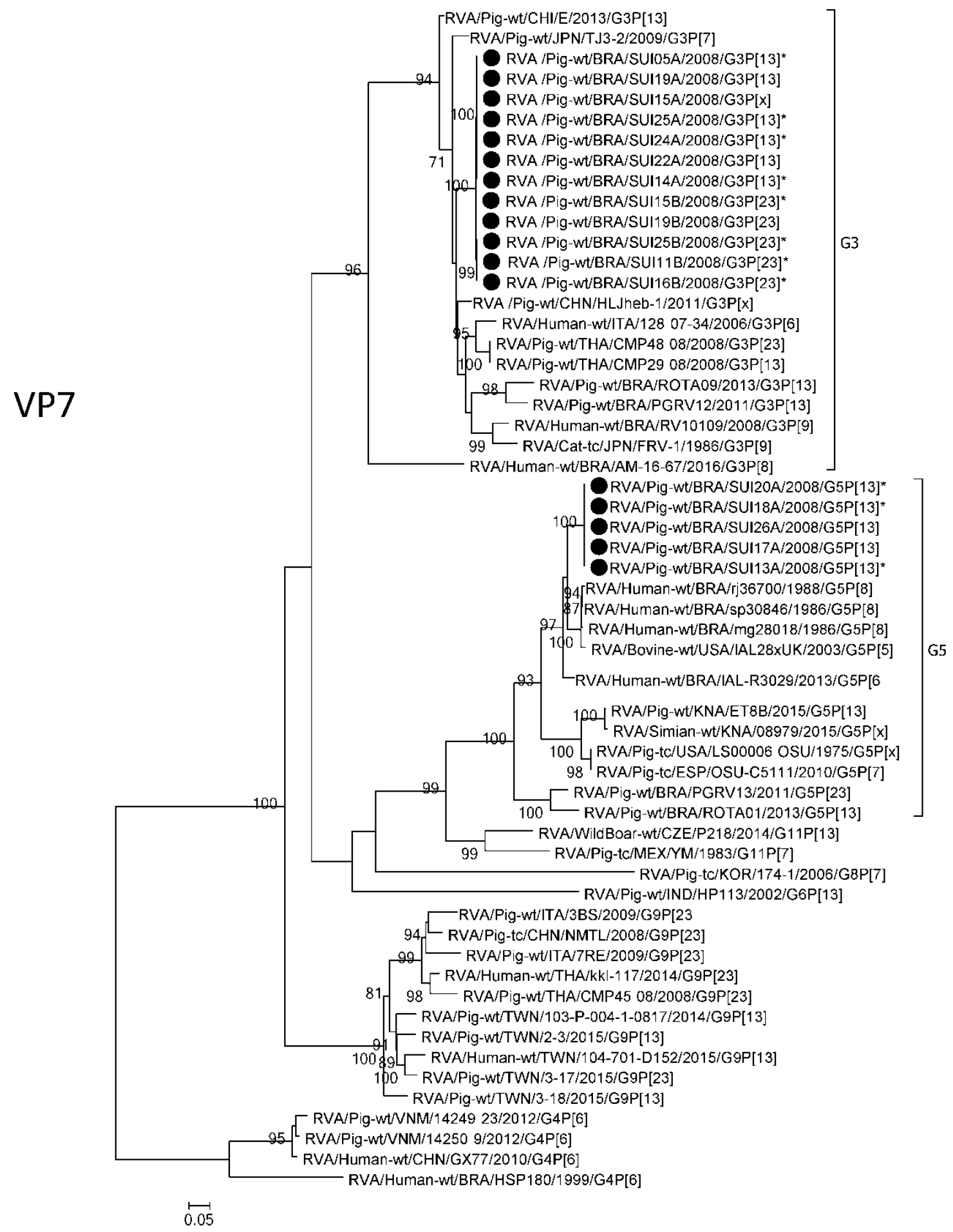


Fig.2 Phylogenetic analyze of VP4 protein of circulating porcine Brazilian RVA strains. The level of bootstrap support is indicated at each node (values $<70 \%$ were omitted). The circle represents the strains of this study. (*) indicates the strains identified in the Camargo, et al., (2012) study

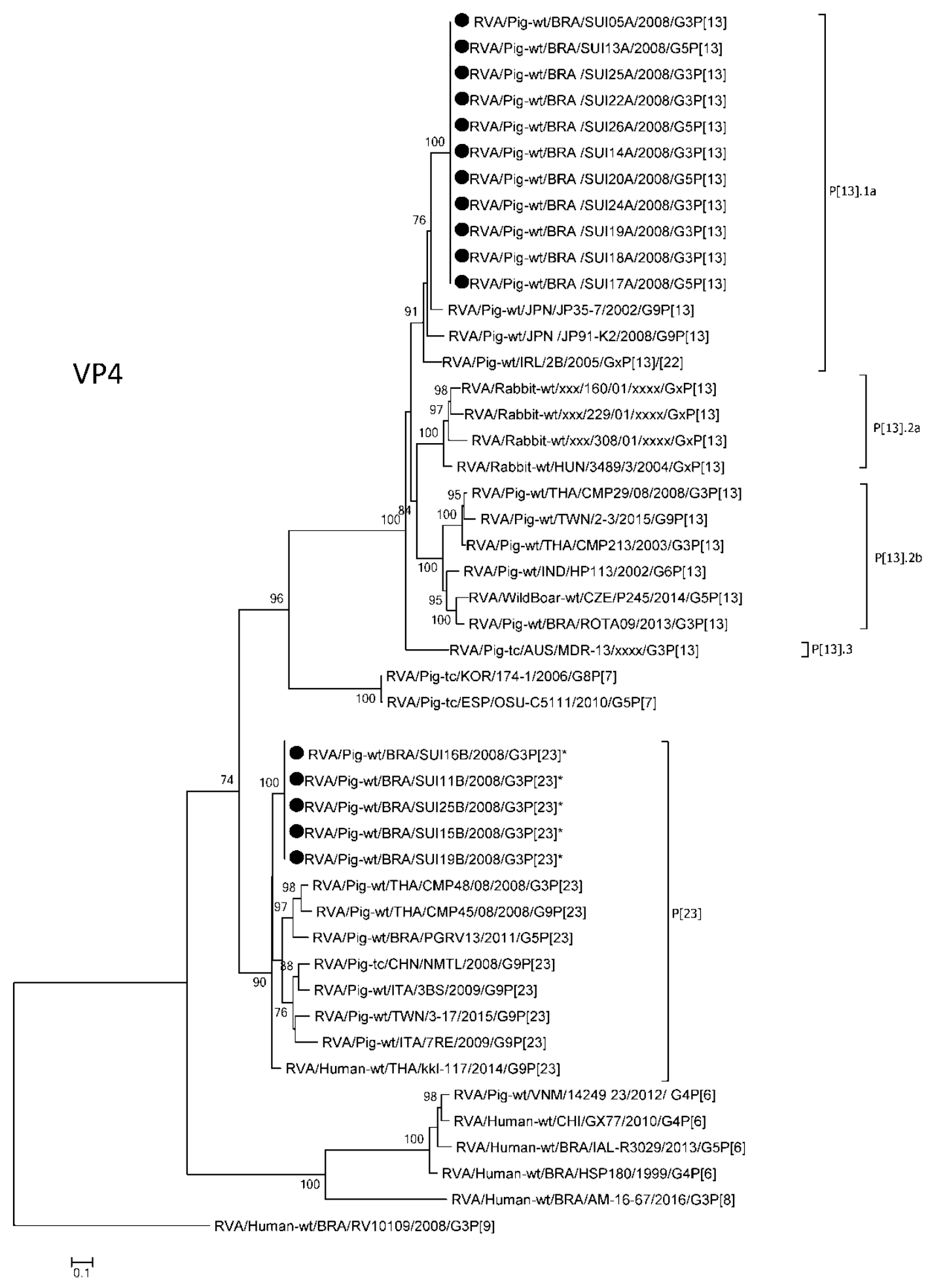


Fig.3 Phylogenetic analyze of VP6 protein of circulating porcine Brazilian RVA strains. The level of bootstrap support is indicated at each node (values $<70 \%$ were omitted). The circle represents the strains of this study

VP6

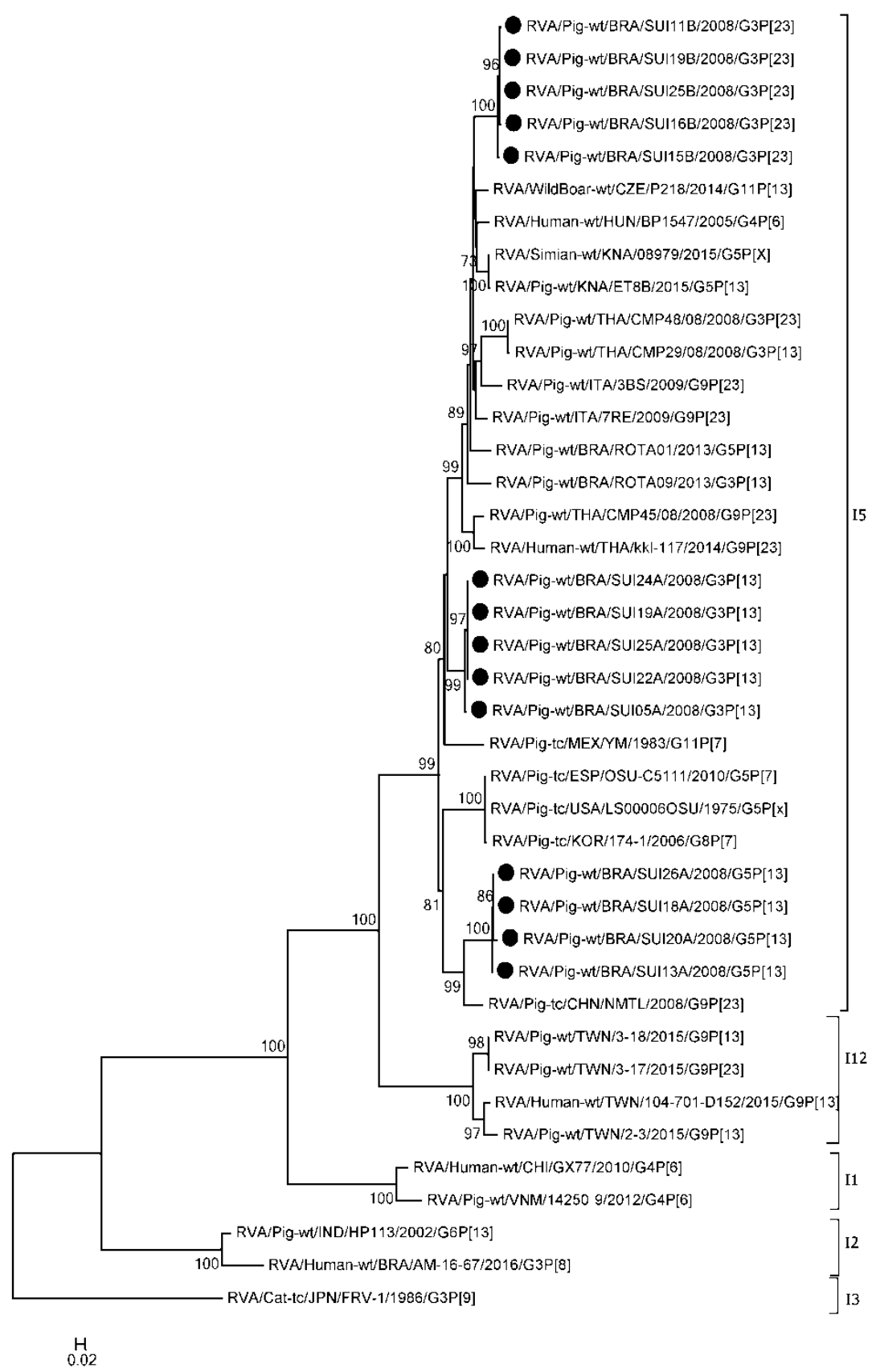


Fig.4 Phylogenetic analyze of VP1 protein of circulating porcine Brazilian RVA strains. The level of bootstrap support is indicated at each node (values $<70 \%$ were omitted). The triangle represents the strains of this study

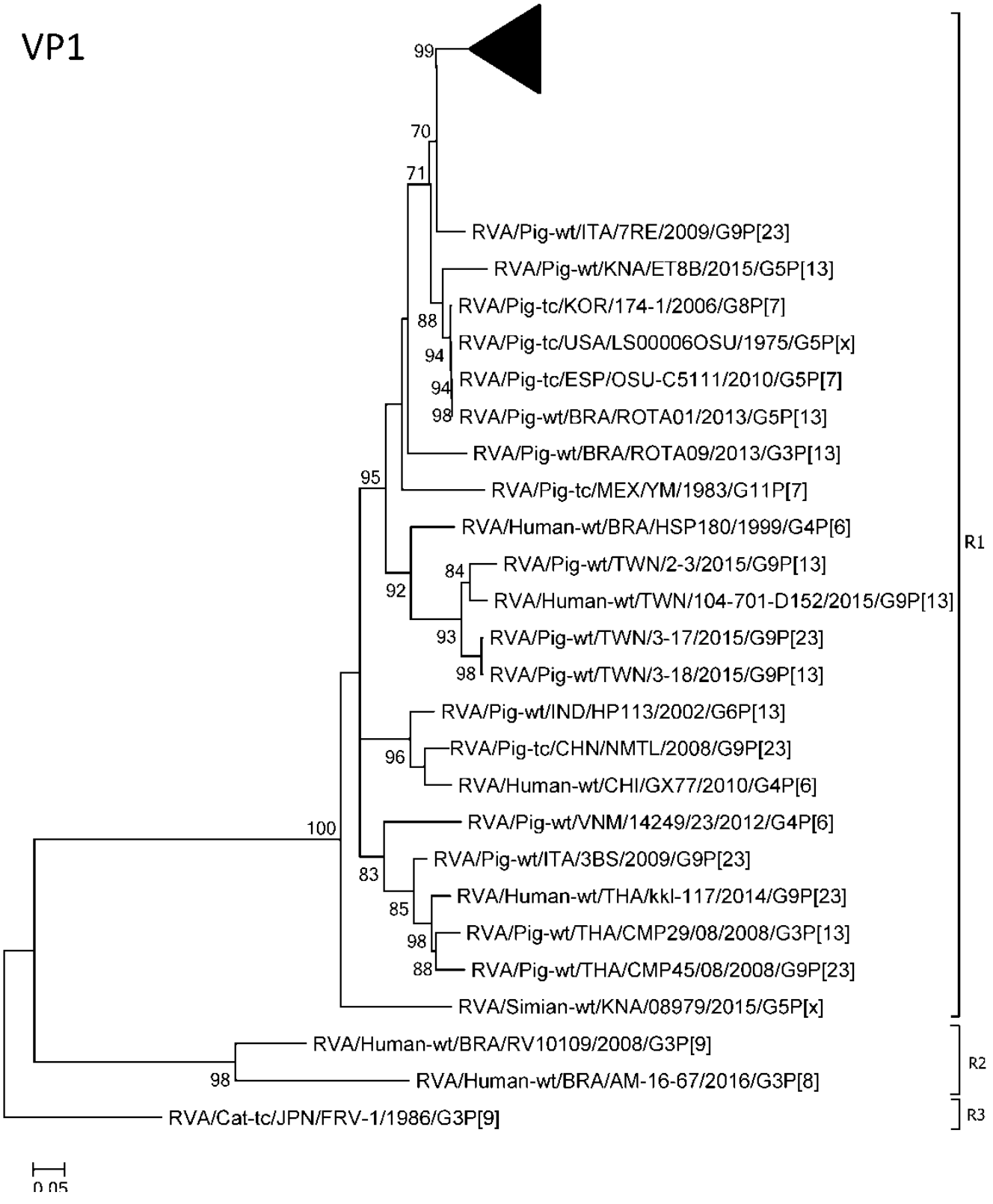


Fig.5 Phylogenetic analyze of VP2 protein of circulating porcine Brazilian RVA strains. The level of bootstrap support is indicated at each node (values $<70 \%$ were omitted). The circle represents the strains of this study

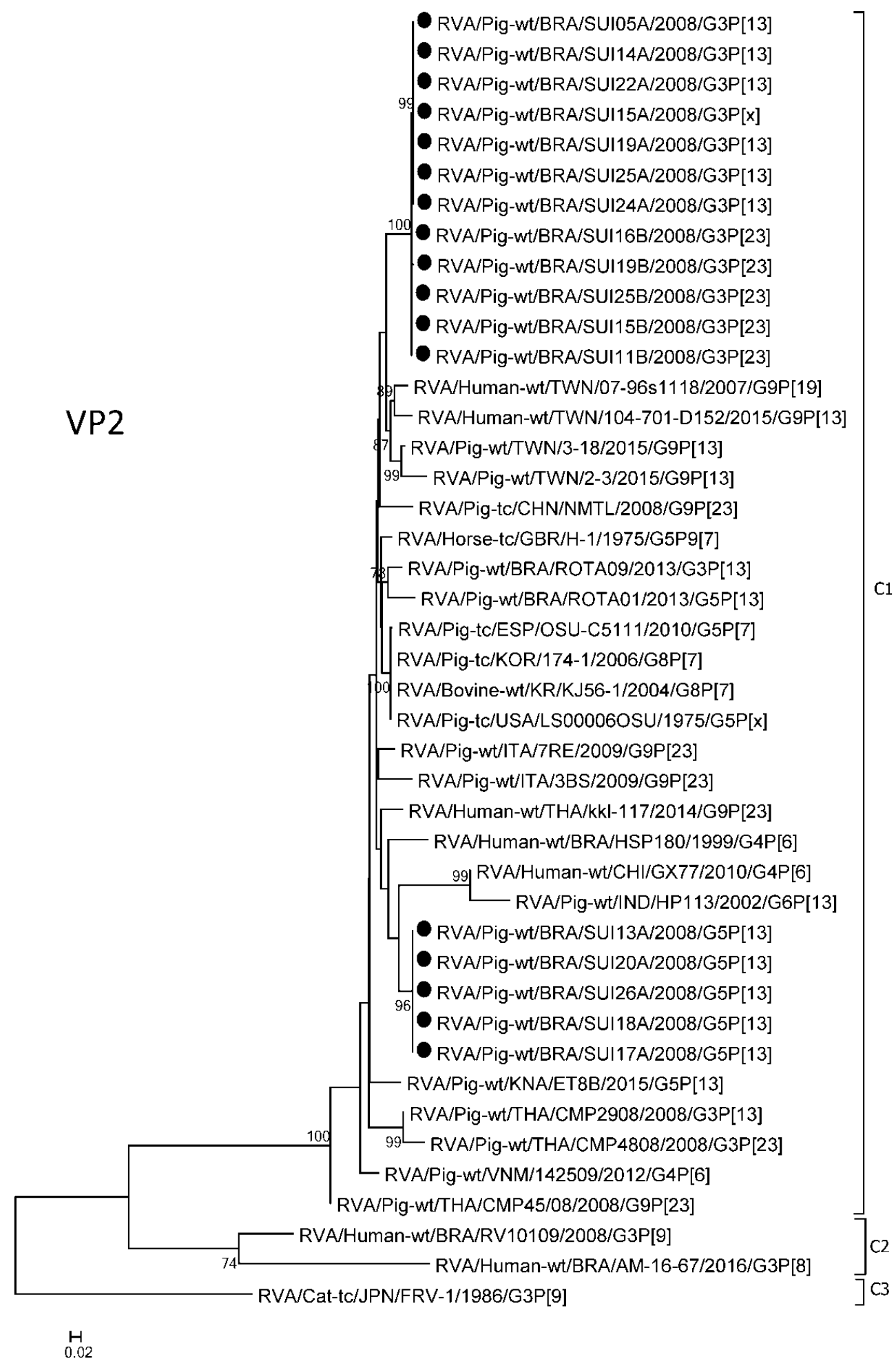


Fig.6 Phylogenetic analyze of VP3 protein of circulating porcine Brazilian RVA strains. The level of bootstrap support is indicated at each node (values $<70 \%$ were omitted). The circle represents the strains of this study

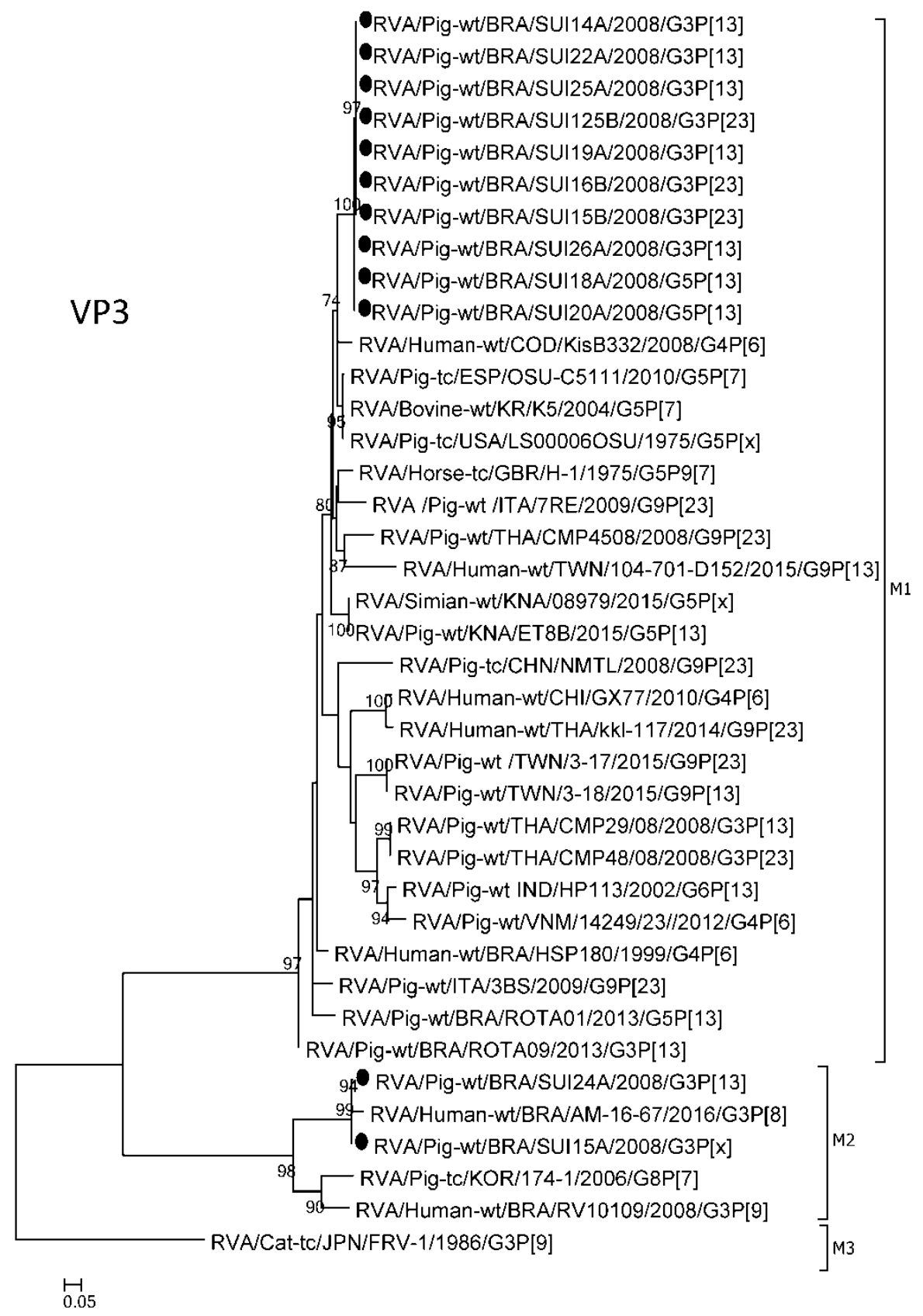


Fig.7 Phylogenetic analyze of NSP1 protein of circulating porcine Brazilian RVA strains. The level of bootstrap support is indicated at each node (values $<70 \%$ were omitted). The circle represents the strains of this study

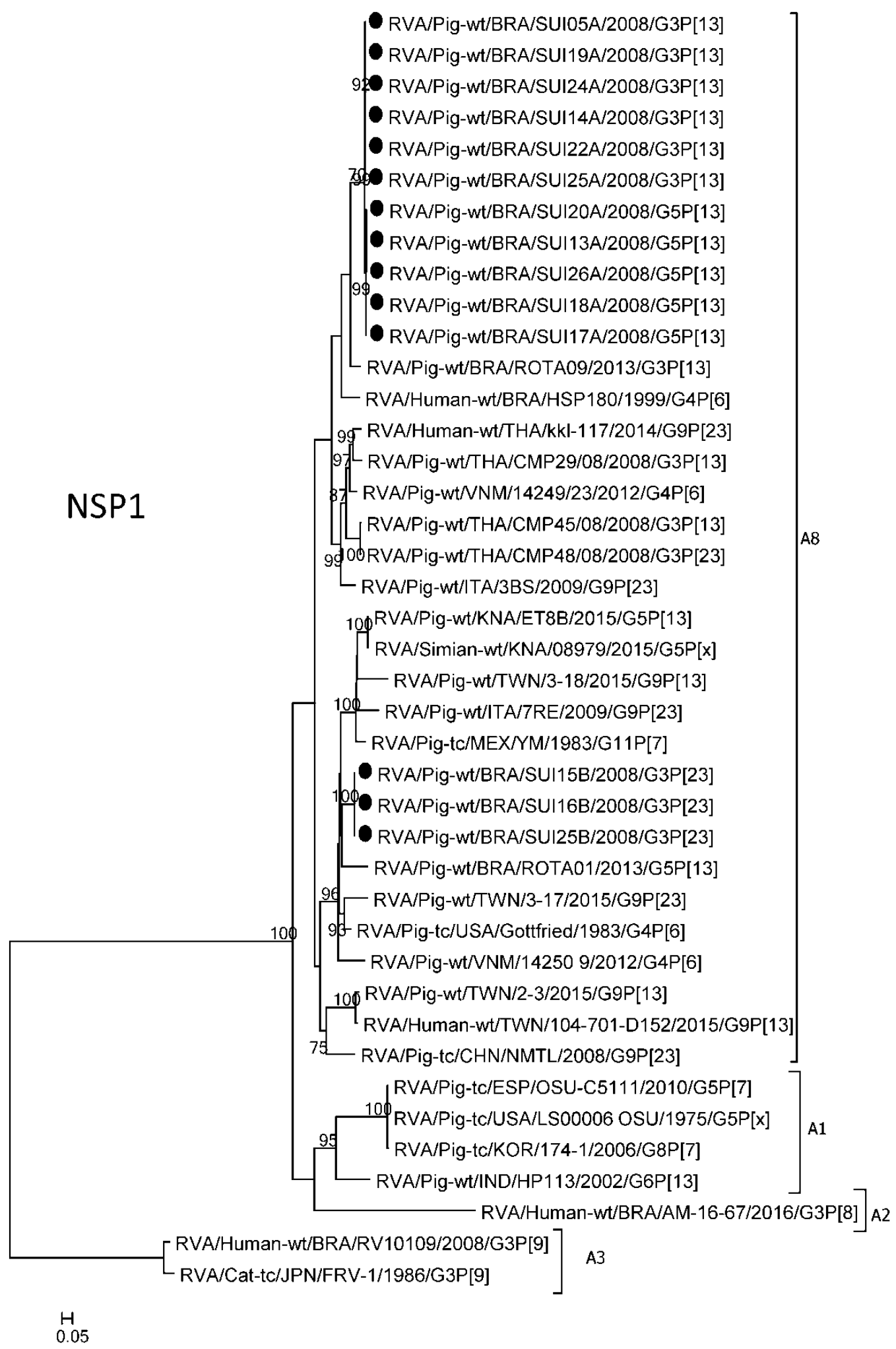


Fig.8 Phylogenetic analyze of NSP2 protein of circulating porcine Brazilian RVA strains. The level of bootstrap support is indicated at each node (values $<70 \%$ were omitted). The circle represents the strains of this study

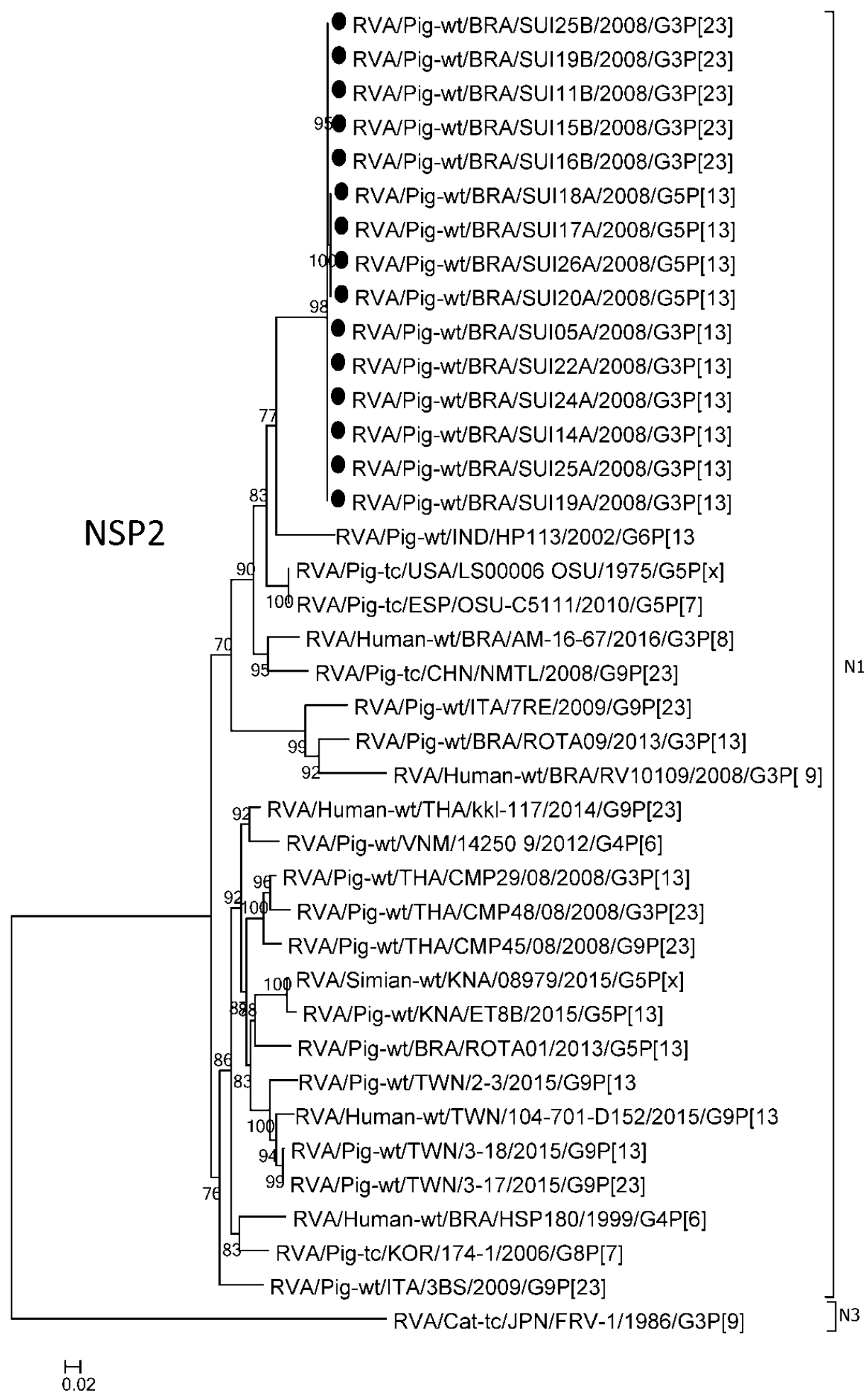


Fig.9 Phylogenetic analyze of NSP3 protein of circulating porcine Brazilian RVA strains. The level of bootstrap support is indicated at each node (values $<70 \%$ were omitted). The circle represents the strains of this study

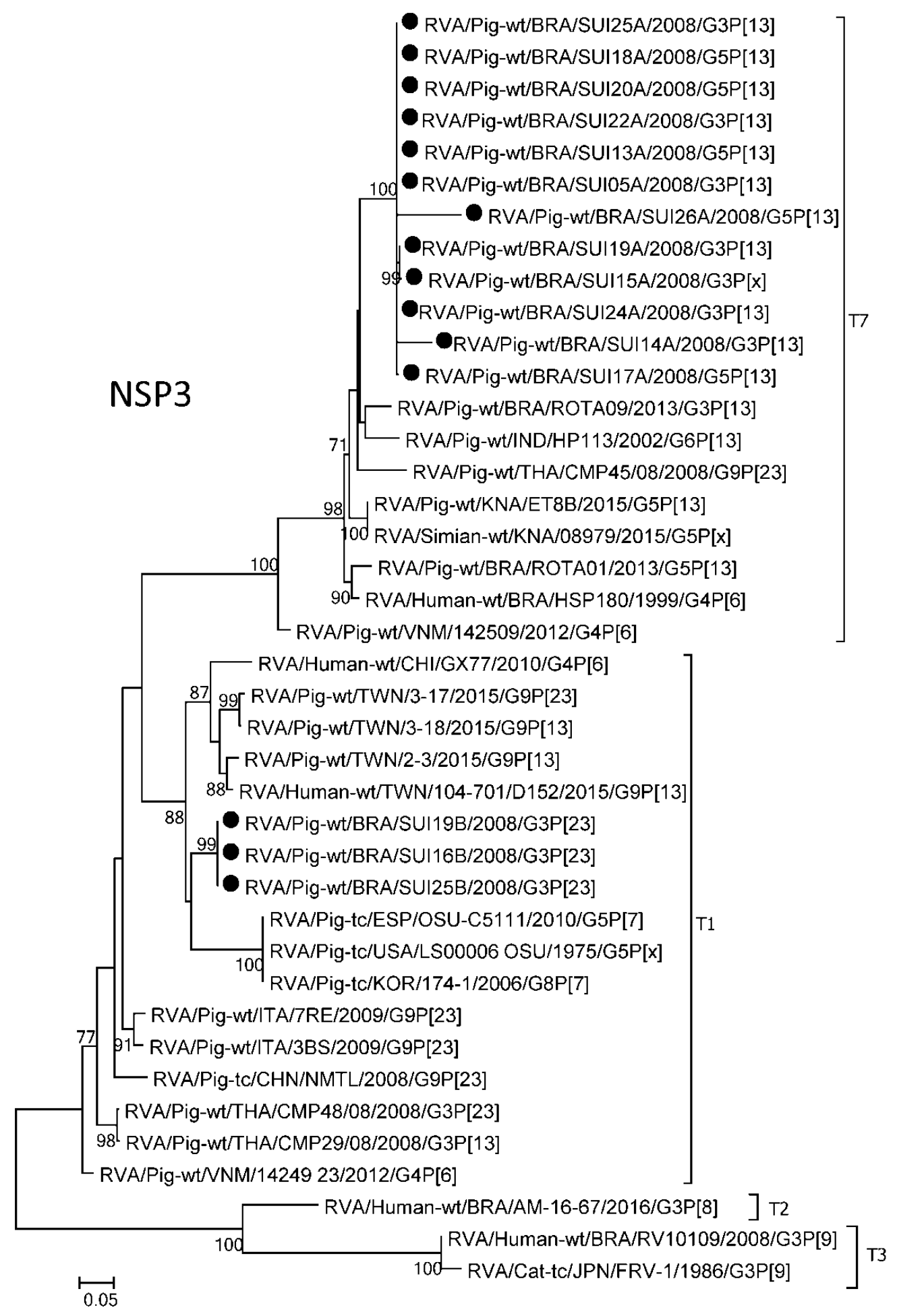


Fig.10 Phylogenetic analyze of NSP4 protein of circulating porcine Brazilian RVA strains. The level of bootstrap support is indicated at each node (values $<70 \%$ were omitted). The triangle represents the strains of this study

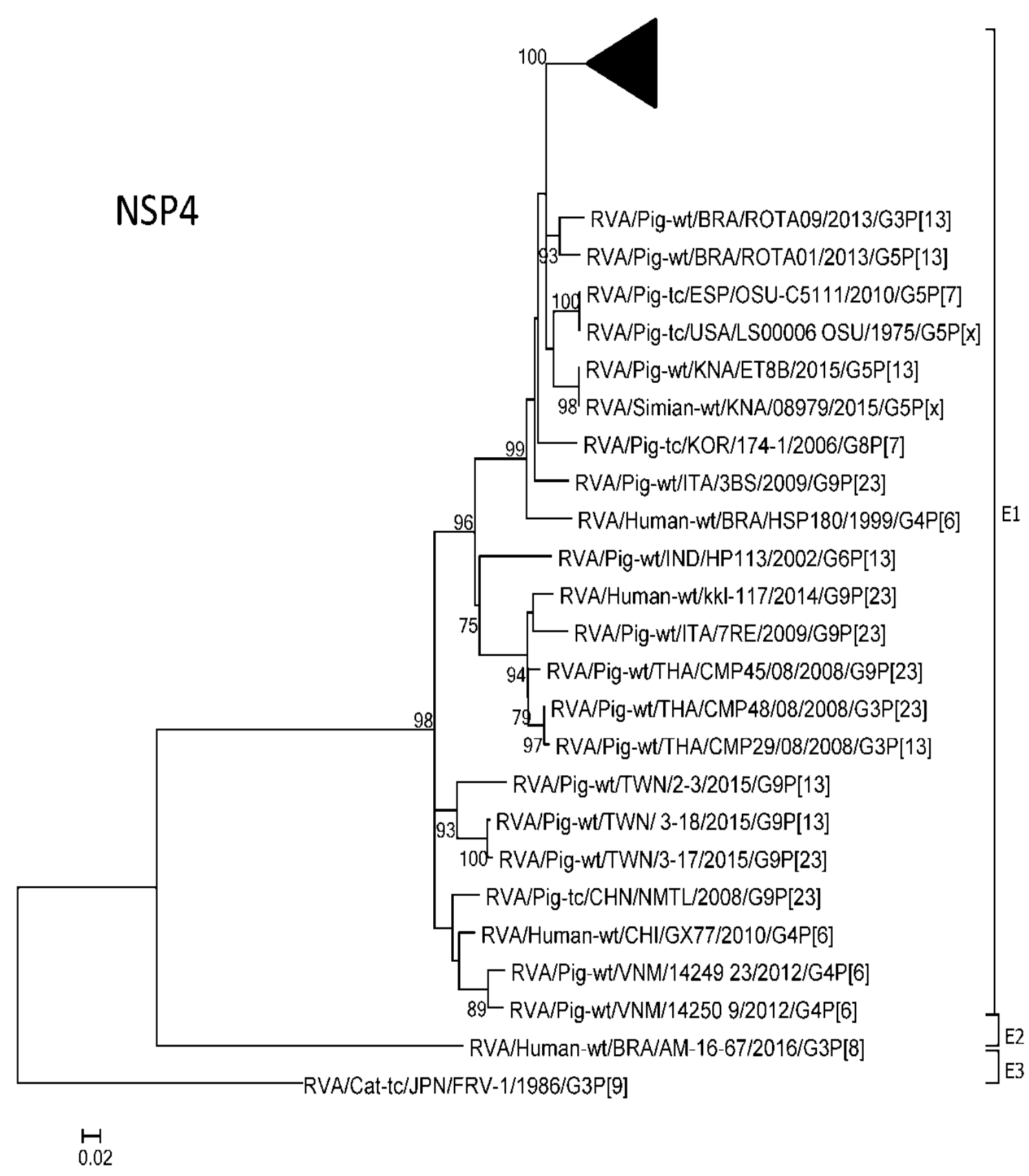


Fig.11 Phylogenetic analyze of NSP5 protein of circulating porcine Brazilian RVA strains. The level of bootstrap support is indicated at each node (values $<70 \%$ were omitted). The triangle represents the strains of this study

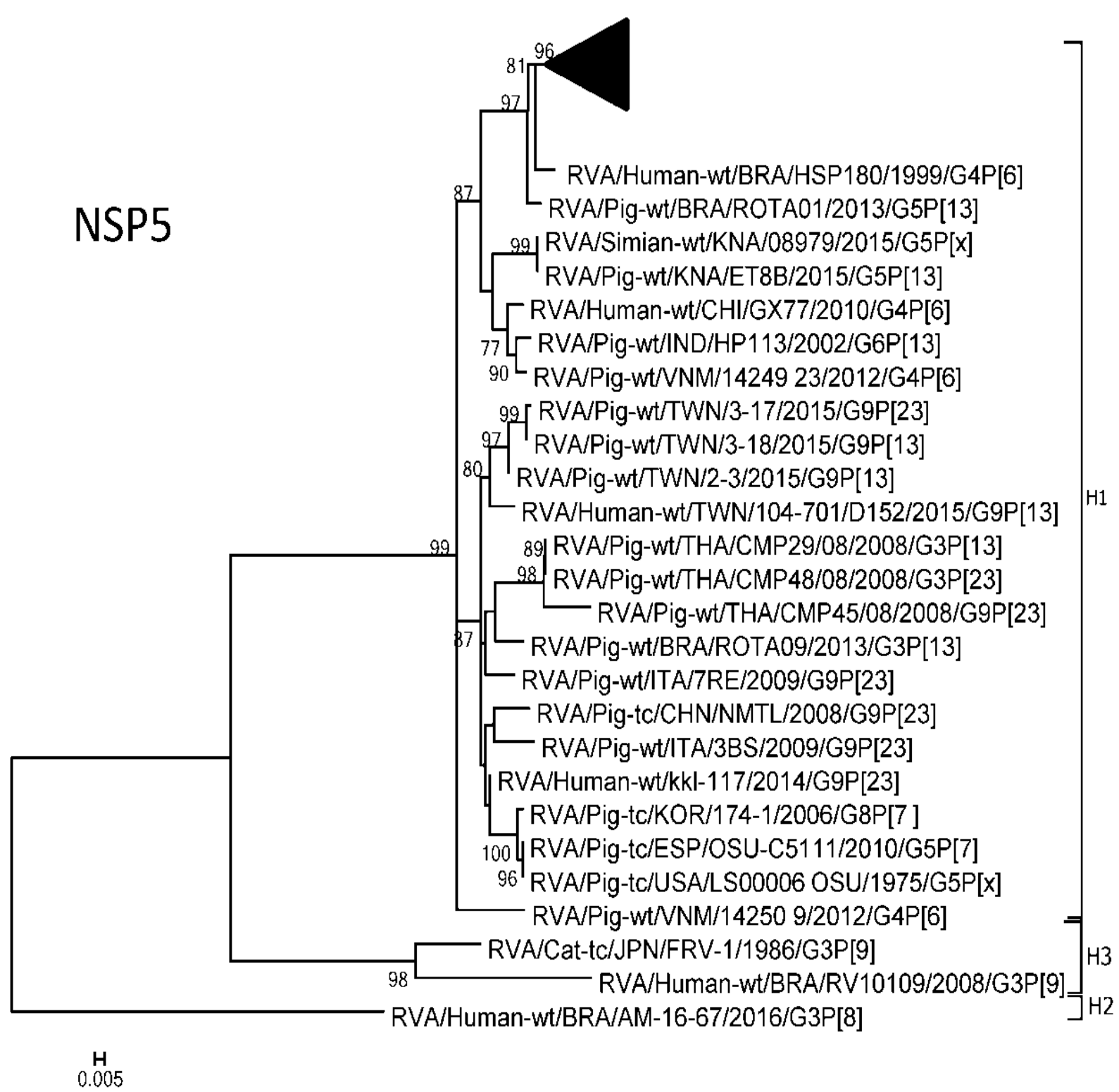


Table.1 Genotypic constellation of the RVA strains used in this study

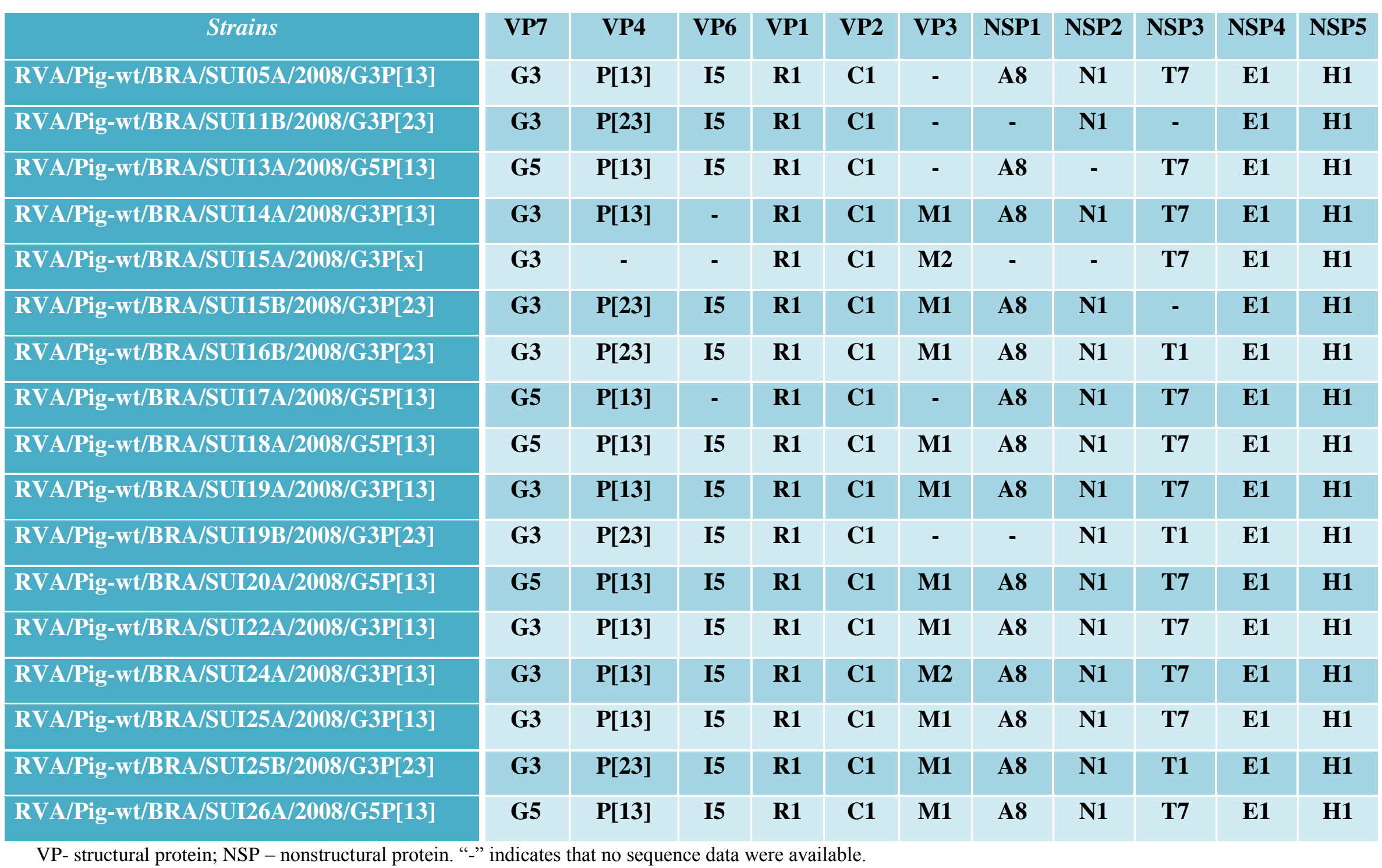


Strains characterized as an M2 genotype showed an $85 \%$ nucleotide similarity with the reassortant strain M2 genotype isolated in swine, which circulated in 2006, originating in South Korea (Figure 6). The VP2 and VP3 genes showed an intimate phylogenetic relationship with genes related to the strains from other mammals.

\section{Phylogenetic analysis of gene coding for non-structural proteins}

All partial sequences of the NSP1 gene analyzed in this study grouped with the A8 genotype, being arranged in two separate branches, demonstrating a similarity with strains circulating within Brazil in humans which was considered a recombinant strain (HSP180; 86\%) - and in swine (ROTA09; 90\%) / (ROTA01; 86\%) (Figure 7). The NSP2 gene, N1 genotype, was shown to be more closely related to pigs, but showed association with human isolates in Brazil (AM-16-67) and Thailand (kkl-117) (88-90\%) (Figure 8). In analysis of the NSP3 gene, T1 genotypes were identified in $20 \%(3 / 15)$ and T7 genotypes in $80 \%(12 / 15)$ of the findings. Phylogenetic analysis indicated that all sequences appeared to be of porcine origin (91\%). The finding of T7 genotypes in this study was expected, since this genotype is commonly found in swine around the world (Figure 9). For the NSP4 and NSP5 genes, it was possible to identify the $\mathrm{E} 1$ and $\mathrm{H} 1$ respective genotypes for all strains of isolated RVA. The phylogenetic analysis of NSP4 showed a relationship between strains in the study and other strains of pigs (93\%) around the globe. The nucleotide similarities between RVA strains of porcine genes and of a simian strain (08079) (93\%), as well as a recombinant human strain (HSP 180) (91\%), were also observed (Figure 10). In relation to the NSP5 gene, the sequences studied also demonstrated high nucleotide similarity with the recombinant strain HSP180 (99\%) isolated in humans in Brazil in 1999, suggesting that transmission between species occurred, in which reassortment events were observed (Figure 11).

Pig farming is an activity of great social and economic importance in Brazil, responsible for producing just over 3.5 million tons of pork in 2015; the country being considered the fourth largest producer and exporter of this product in the world (ABPA, 2016). However, the risk of contamination from various diseases in breeding sites imposes upon producers a necessity of maintaining control over all productive stages. The surveillance of RVA infections in northern Brazilian pig populations is limited and not effectively performed over the diversity of RVA strains in swine. This study was one of a pioneering nature in the investigation of every RVA gene among pigs in the metropolitan area of Belém, Pará, where previous findings showed a prevalence of $9.9 \%$ (17/172) (Camargo et al., 2012). Several studies indicate that porcine rotaviruses may be a potential source of transmission between species involving humans (Martella et al., 2005; Mascarenhas et al., 2007; Luchs et al., 2016). In the phylogenetic analysis in this study, it was observed that RVA genes infecting pigs presented a high degree of nucleotide similarity to strains from other hosts, including humans. Little is known about the zoonotic potential of rotaviruses in Brazil. However, it is widely known that transmission between species of RVA between humans and pigs can occur frequently, as observed in several studies (Zeller et al., 2012; Esona et al., 2017). An epidemiological analysis conducted by $\mathrm{Wu}$ et al., (2017) provides a conceivable scenario of events with regard to the direct transmission of porcine RVA strains, this potentially infecting humans. Pigs in the study were infected by genotypes G3P[23], G3P[13] and G5P[13], which are commonly or even 
exclusively detected in swine. These data demonstrate that three different combinations of RVA circulated in a single population of swine. Previous epidemiological studies have shown that the combination of the G3, G5 and G9 genotypes with $\mathrm{P}[13]$ and $\mathrm{P}[23$ ] revealed that these were the most common genotypes in some geographical areas of Brazil, possessing the ability to infect pigs (Molinari et al., 2016; Silva et al., 2015; Tonietti et al., 2013). It was well established that such genotypes had already been reported sporadically in other parts of the world (Matthijnssens et al., 2011). More recently, Dóró et al., (2015) reported G5 (46\%) and G3 (11\%) genotypes as the most prevalent in pigs, globally speaking. Specifically, the G3 genotypes of this study were more closely related to those of other Brazilian strains in pigs. G5 strains, conversely, clustered with a high similarity to human strains. This may be strongly associated with intragenomic reassortment events as a result of zoonotic transmission. Based on analysis of the G5 strains, da Silva et al., (2011) speculated that the G5 genotype that circulates in humans inside Brazil may be the result of two independent events of zoonotic transmission, most likely from swine. Tonietti et al., (2013) reported that the first detection of $\mathrm{P}[23]$ in Brazil was associated with G5 in samples that were collected in 2011, but the P[23] of this present study had been collected in 2008, showing that this $\mathrm{P}$ type had previously circulated in the North region, associated with genotype G3 (Camargo et al., 2012). The $\mathrm{P}[23]$ genotype has repeatedly been detected in Asia (Kim et al., 2012; Okitsu et al., 2013), having also occasionally been reported in Europe and other continents (Papp et al., 2013). In addition to the $P[23]$, eleven $P[13]$ strains (65\%), in combination with G3 or G5, were isolated from diarrheic pigs. These strains were more closely related to porcine RVA strains isolated from Japan (JP35-7 / JP91-K2) and Ireland (2B). These findings allowed us to reasonably suggest that the $\mathrm{P}[13]$ strains frequently detected in pigs will group into different clades. The present analysis revealed that genes VP1, VP2, VP3, NSP2, NSP3, NSP4 and NSP5 were associated with the genotypes R1, C1, M1, $\mathrm{N} 1, \mathrm{~T} 1, \mathrm{E} 1$ and $\mathrm{H} 1$ respectively, which are related to the genetic backbone identified in humans. Matthijnssens et al., (2008) have suggested that porcine RVA strains and the human Wa-like constellation have a common evolutionary ancestor, since genotype 1 genes can be found in both species. The findings of Theuns et al., (2015) propose an evolution in the relationship between the RVA of pigs and humans. However, it is noteworthy that a phylogenetic comparison of the sequences studied revealed that despite a nucleotide similarity with the Wa-like constellation, the strains had evolved from a porcine origin. Although most strains of the NSP3 and VP3 genes shared the Wa-like genotype 1 constellation, genotypes M2 (17\% 2/12) and T7 (80\% 12/15) were also identified, which are commonly found in strains of the DS-1like and porcine-like constellations, respectively (Matthijnssens et al., 2008). Interestingly, it has been observed that the M2 genotype has been extensively described as affecting humans and cattle, and less frequently, giraffes, rabbits, antelopes, camelids, goats and swine. Therefore, the phylogenetic analysis conducted in the present analysis supports the view that isolated M2 strains contain the bovine-like genomic segment, and these were indeed grouped with those strains of the bovine and swine recombinant genomic segments. At the molecular level, the VP3 segment is referred to as one of the genes involved in the restriction and/or virulence of several hosts; however, further studies are needed to elucidate these characteristics in rotavirus infections. According to Monini et al., (2014), the high prevalence of the T7 genotype almost certainly confirms the theory that this 
genotype is of porcine origin rather than typical to humans (Martel-Paradis et al., 2012; Okitsu et al., 2013; Zeller et al., 2012). T7 genotypes have been increasingly found in pigs, whereas previously only $\mathrm{T} 1$ genotypes were detected (Papp et al., 2013; Monini et al., 2014). Our findings from T7 suggest that such a genotype was already circulating in Pará, North region of Brazil, before the period reported in the study by Silva et al., (2015) which refers to $\mathrm{T} 7$ for the first time in Brazil - at different farms in the states of São Paulo and MatoGrosso. Several studies corroborate our findings in reporting high levels of genetic similarity between human and animal strains (Matthijnssens et al., 2006; Martella et al., 2010). In addition, this study reaffirms heterogeneity among strains of porcine origin that has been described in different locations, including Brazil. Papp et al., (2013) reported that the genetic diversity found in pigs indicates that transmission between species contributes to the evolution of unusual and recombinant natural strains in a post-vaccine scenario. It has already been established that the introduction of an RVA vaccine into the national immunization program contributed to a significant reduction in the frequency of this infection in the pediatric population (Zeller et al., 2012). However, this pathogen may be associated with severe diseases in domestic animals, and surveillance of its genotypic variability is paramount in monitoring the emergence of new circulating strains in animals; since this emergence, when derived from a transmission between species, has implications for the successful application of rotavirus vaccine strategies in humans (Lachapelle et al., 2014; Papp et al., 2013). In conclusion, the results of this study show that our observations provide relevant information on the dynamic interactions between human and porcine rotavirus strains, and that they constitute an increase in knowledge on the diversity of RVA strains in animal reservoirs circulating in the Amazon region, clearly showing the prominent role of rotaviruses as a cause of diarrhea in pigs, and their potential ability to cross the barrier between species.

\section{Conflict of Interest Statement}

None of the authors of this paper have a financial or personal relationships with other peopleor organizations that could inappropriately influence or bias the content of the paper.

\section{Acknowledgments}

The authors wish to thank the Evandro Chagas Institute for its financial, technical, and scientific support in the execution of this work. Thanks also are given to the Amazonia Paraense Foundation for Research Support (Fapespa) for awarding its Doctorate scholarships.

\section{References}

Alfieri, A.A., Leite, J.P.G., Alfieri, A.F., Jiang, B., Glass, R.I., Gentsch, J.R. 1999. Detection of field isolates of human and animal group $C$ rotavirus by reverse transcriptionpolymerase chain reaction and digoxigenin-labeled oligonucleotide probes. Journal of Virological Methods, v.83, p.35-43.

Associação Brasileira De Proteína Animal (ABPA). Vendas para o Leste Europeu impulsionam e exportações de carne suína crescem 4,4\% em 2015. São Paulo, 2015. Available: http://abpabr.com.br/noticia/vendas-para-o-LesteEuropeu-impulsionam-e-exportaçõesde-carne-suína-crescem-44-em-20151362. Access: 2018.

Bányai K, Kemenesi G, Budinski I, Földes F, Zana B, Marton S, Varga-Kugler R, Oldal M, Kurucz K, Jakab F. 2017. Candidate new rotavirus species in 
Schreiber's bats, Serbia. Infect. Genet. Evol. v. 48, p. 19-26.

Barbosa, Bernardes, Beserra, Gregori. 2013. Molecular Characterization of the Porcine Group A Rotavirus NSP2 and NSP5/6 Genes from São Paulo State, Brazil, in 2011/12. Research Article. Volume 2013, 7 pages.

Boom R, Sol C J, Salimans M M, Jansen C L, Wertheim-Van P M, Noordaa J. 1990. Rapid and simple method for purification of nucleic acids. J. Clin. Microbiol., v.28, p.495-503.

Camargo D. S., Matos, J. C. S., Guerra S. F. S., Soares, L. S., Neri, D.L., Maestri, R. P., Oliveira, A.S., Oliveira, D.S., Gabbay, Y.B., Linhares, A.C., Mascarenhas, J.D.P. 2012. Identification of rotavirus $G$ and $P$ genotypes in nursing and weaning piglets in the metropolitan region of Belém, northern Brazil. Rev. PanAmaz. Saude.v.3, n.3.

Chang; Kim; Saif. 2012. Rotavirus and reovirus. In ZIMMERMAN; karriker; RAMIREZ; SCHWARTZ; STEVESON. Diseaseofswine. 10 ed. United Kingdom: Wiley-Blackwell, p. 621-634.

Cunliffe NA, Woods PA, Leite JP, Das BK, Ramachandran M, Bhan MK, Hart CA, Glass RI, Gentsch JR. 1997. Sequence analysis of NSP4 gene of human rotavirus allows classification into two main genetic groups.J MedVirol. Sep;53(1):41-50.

Da Silva, M.F., Tort, L.F., Goméz, M.M., Assis, R.M., Volotão EDE, M., De Mendonca, M.C., Bello, G., Leite, J.P. 2011. VP7 gene of human rotavirus $A$ genotype G5: phylogenetic analysis reveals the existence of three different lineages worldwide. J. Med. Virol. 83; 357-366.

Doró, R., Farkas, S., Martella, V., Bányai, K. 2015. Zoonotic transmission of rotavirus: surveillance and control. Expert ReviewofAnti-infectiveTherapy, vol. 13.

Efetivos Dos Rebanhos. 2016. Instituto Brasileiro de Geografia e Estatística (IBGE). Access: www.ibge.gov.br.

Esona MD, Roy S, Rungsrisuriyachai K, Sanchez J, Vasquez L, Gomez V, Rios LA, Bowen MD, Vazquez M. 2017. Characterization of a triplerecombinant, reassortant rotavirus strain from the Dominican Republic. J Gen Virol. Feb; 98(2):134-142.

Gentsch Jr, Glass Ri, Woods P, Gouvea V, Gorziglia M, Flores J, Das Bk, Bhan Mk. 1992. Identification of group A rotavirus gene 4 types by polymerase chain reaction. J Clin Microbiol. Jun; 30(6):1365-73.

Gouvea V, Glass Ri, Woods P, Taniguchi K, Clark Hf, Forrester B, Fang Zy. 1990. Polymerase chain reaction amplification and typing of rotavirus nucleic acid from stool specimens. J ClinMicrobiol. Feb; 28(2):276-82.

International Committee on Taxonomy of Viruses (ICTV). 2017. Access: https://talk.ictvonline.org/. Available: september,2018.

Katoh, K., Standley, D.M. 2013. MAFFT Multiple Sequence Alignment Software Version 7: Improvements in Performance and Usability. Mol. Biol. Evol., Apr; 30(4): 772-780.

Kearse, Moir, Wilson, Stones-Havas, Cheung, Sturrock, Buxton, Cooper, Markowitz, Duran, Thierer, Ashton, Meintjes and Drummond. 2012. Geneious Basic: An integrated and extendable desktop software platform for the organization and analysis of sequence data. Bioinformatics. Jun 15; 28(12): 16471649.

Kim, H. H., Matthijnssens, J., Kim, H. J., Kwon, H. J., Park, J. G., Son, K. Y., and Yang, D. K. 2012. Full-length genomic 
analysis of porcine G9P [23] and G9P [7] rotavirus strains isolated from pigs with diarrhea in South Korea.Infection, geneticsandevolution, 12(7), 14271435 .

Lachapelle, Sohal, Lambert, Brassard, Fravalo, Letellier, L'homme. 2014. Genetic diversity of group A rotavirus in swine in Canada. Arch Virol. 159:1771-1779.

Lanata C.F., Fischer-Walker C.L., Olascoaga A.C., Torres C.X., Aryee M.J., Black R.E., Child Health Epidemiology Reference Group of the World Health Organization and UNICEF. 2013. Global Causes of Diarrheal Disease Mortality in Children <5 Years of Age: A Systematic Review. Plos One. Sep 4; 8(9):e72788.

LARSSON, A. 2014.AliView: a fast and lightweight alignment viewer and editor for large datasets. Bioinformatics, 30(22), 3276-3278.

Luchs, A., Timenetsky, M.C.S. 2016. Group A rotavirus gastroenteritis: post-vaccine era, genotypes and zoonotic transmission. einstein. 14(2):278-87.

Martella, V., Bányai, K., Ciarlet, M., IturrizaGómara, M., Lorusso, E., Grazzia, S., Arista, S., Decaro, N., Elia, G., Cavalli, A., Corrente, M., Lavazza, A., Baselga, R., Buonavoglia, C. 2006. Relationships among porcine and human $\mathrm{P}[6]$ rotaviruses: Evidence that the different human $\mathrm{P}[6]$ lineages have originated from multiple interspecies transmission events. Virol. 344, p. 509-519.

Martella, V., Bányai, K., Matthijnssens, J., Buonavoglia, C., Ciarlet, M. 2010. Zoonotic aspects of rotaviruses.Veterinary Microbiology. p. 246-255.

Martel-Paradis, O., Laurin, M. A., Martella, V., Sohal, J. S., and L'homme, Y. 2013. Full-length genome analysis of G2, G9 and G11 porcine group A rotaviruses.
Veterinarymicrobiology, 162(1), 94102.

Marthaler D, Homwong N, Rossow K, Culhane M, Goyal S, Collins J, Matthijnssens J, Ciarlet M. 2014. Rapid detection and high occurrence of porcine rotavirus $\mathrm{A}, \mathrm{B}$, and $\mathrm{C}$ by $\mathrm{RT}$ qPCR in diagnostic samples.J Virol Methods. Dec; 209: 30-4.

Mascarenhas, J. D. P., Leite, J. P. G., Lima, J. C., Heinemann, M. B., Oliveira, D. S., Araújo, I. T., Soares, L. S., Gusmão, R. H. P., Gabbay, Y. B., Linhares, A. C. 2007. Detection of a neonatal human rotavirus strain with VP4 and NSP4 genes of porcine origin. J. Med. Microbiol. v. 56, n. 4, p. 524-532.

Matthijnssens J, Ciarlet M, Mcdonald SM, Attoui H, Banyai K, Brister JR, Buesa J, Esona MD, Estes MK, Gentsch JR, Iturriza-Gómara M, Johne R, Kirkwood CD, Martella V, Mertens PP, Nakagomi O, Parreño V, Rahman M, Ruggeri FM, Saif LJ, Santos N, Steyer A, Taniguchi K, Patton JT, Desselberger U, Van Ranst M. 2011. Uniformity of rotavirus strain nomenclature proposed by the Rotavirus Classification Working Group (RCWG). Arch Virol. 156(8):1397-1413.

Matthijnssens J, Rahman M, Martella V, Xuelei Y, De Vos S, De Leener K, Ciarlet M, Buonavoglia C, Van Ranst M. 2006. Full genomic analysis of human rotavirus strain B4106 and lapine rotavirus strain 30/96 provides evidence for interspecies transmission. $\mathbf{J}$ Virol. Apr; 80(8): 3801-10.

Matthijnssens, J., De Grazia, S., Piessens, J., Heylen, E., Zeller, M., Giammanco, G. M., and Van Ranst, M. 2011. Multiple reassortment and interspecies transmission events contribute to the diversity of feline, canine and feline/canine-like human group A 
rotavirus strains. Infection, Genetics and Evolution, 11(6), 1396-1406.

Matthijnsses J., Ciarlet, M., Heiman, E., Arijis, L., Delbek, T., Mcdonald, S., Palombo, E., Iturriza-Gomara, M., Maes, M., Patton, J., Rahman, M., Van Rast, M. 2008. Full genome-based classification of rotaviruses reveals a common origin between human Wa-like and porcine rotavirus strains and human DS-1-like and bovine rotavirus strains. Journal of Virology, v. 82, n. 7, p. 32043219.

Mihalov-Kovács E, Gellért Á, Marton S, Farkas SL, Fehér E, Oldal M, Jakab F, Martella V, Bányai K. 2015. Candidate New Rotavirus Species in Sheltered Dogs, Hungary. Emerging Infectious Diseases. v. 21, n. 4, p. 660-663.

Minh, B.Q., Nguyen, M.T., Von Haeseler, A. 2013. UltrafastApproximation for PhylogeneticBootstrap. Mol BiolEvol. May; 30(5): 1188-1195.

Molinari B.L., Lorenzetti E., Otonel R.A., Alfieri A.F., Alfieri A.A. 2014. Species $\mathrm{H}$ rotavirus detected in piglets with diarrhea, Brazil, 2012. Emerg. Infect. Dis. V.20. p. 1019-1022.

Molinari BL, Alfieri AF, Alfieri AA. 2015. Genetic variability of VP6, VP7, VP4, and NSP4 genes of porcine rotavirus group $\mathrm{H}$ detected in Brazil. Virus Res. 2; 197: 48-53.

Molinari, B. L. D., Possatti, F., Lorenzetti, E., Alfieri, A. F., \& Alfieri, A. A. 2016. Unusual outbreak of post-weaning porcine diarrhea caused by single and mixed infections of rotavirus groups A, $\mathrm{B}, \mathrm{C}$, and H. Veterinary microbiology, 193, 125-132.

Monini M., Zaccaria G., Ianiro G., Lavazza A., Vaccari G., Ruggeria F.M. 2014. Full-length genomic analysis of porcine rotavirus strains isolated from pigs with diarrhea in Northern Italy. Infection,
Genetics and Evolution. Vol 25, Pages 4-1.

Nguyen L.T., Schmidt H.A., Von Haeseler A., Minh B.Q. 2015. Iq-Tree: a fast and effective stochastic algorithm for estimating maximum-likelihood phylogenies. MolBiolEvol. Jan; 32(1):268-74.

Okitsu S., Khamrin P., Thongprachum A., Kongkaew A., Maneekarn N., Mizuguchi M., Hayakawa S., Ushijima H. 2013. Whole-genomic analysis of G3P[23], G9P[23] and G3P[13] rotavirus strains isolated from piglets with diarrhea in Thailand, 2006-2008. Infect. Genet. Evol. 18, 74-86.

Papp H, László B, Jakab F, Ganesh B, De Grazia S, Matthijnssens J, Ciarlet M, Martella V, Bányai K. 2013. Review of group A rotavirus strains reported in swine and cattle. Vet Microbiol. 30; 165(3-4):190-9.

Sanger, F., Nicklen, S., and Coulson, A. R. 1977. DNA sequencing with chainterminating inhibitors.Proc. Natl. Acad. Sci. USA 74, 5463-5467.

Silva, F., Espinoza, L., Tonietti, P., Barbosa, B., Gregori, F. 2015. Whole-genomic analysis of 12 porcine group A rotaviruses isolated from symptomatic piglets in Brazil during the years of 2012-2013. Infection, Genetics and Evolution, v. 32, p. 239-254.

Silva; Tonietti; Espinoza; Brandão; Richtzenhain; Gregori. 2014. Development of primers for sequencing the NSP1, NSP3, and VP6 genes of the group A porcine rotavirus. Semina: Ciências Agrárias, Londrina, v. 35, n. 2, p. 901-904.

Tamura, K., Stecher G., Peterson D., Filipski A., Kumar S. 2013. MEGA6: Molecular Evolutionary Genetics Analysis Version 6.0. MolBiolEvol. Dec; 30(12): 27252729. 
Theuns, S., Heylen, E., Zeller, M., Roukaerts, I., Desmarets, L., Van Ranst, M., Nauwynck, H., Matthijssens, J. 2015. Complete genome characterization of recent and ancient Belgian pig group A rotaviruses and assessment of their evolutionary relationship with human rotaviruses. JournalofVirology, v. 89, n. 2, p. 1043-1057.

Tonietti PO, Hora AS, Silva FD, Ruiz VL, Gregori F. 2013. Phylogenetic analyses of the VP4 and VP7 genes of porcine group A rotaviruses in Sao Paulo State, Brazil: first identification of G5P[23] in piglets. J. Clin. Microbiol. 51(8):27503.

Varghese V, Ghosh S, Das S, Bhattacharya SK, Krishnan T, Karmakar P, Kobayashi N, Naik T 2006. Characterization of VP1, VP2 and VP3 gene segments of a human rotavirus closely related to porcine strains. Virus Genes 32: 241-247.

Vlasova, Amimo, Saif. 2017. Porcine Rotaviruses: Epidemiology, Immune
Responses and Control Strategies. Viruses. Mar 18; 9(3).

Wakuda M., Ide, Sasaki, Komoto, Ishii, Sanekata, Taniguchi. 2011. Porcine Rotavirus Closely Related to Novel Group of Human. Rotaviruses; Emerg Infect Dis., Aug; 17(8): 1491-1493.

Wu FT, Bányai K, Lin JS, Wu HS, Hsiung CA, Huang YC, Hwang KP, Jiang B, Gentsch JR. 2012. Putative canine origin of rotavirus strain detected in a child with diarrhea, Taiwan. Vector Borne Zoonotic Dis. 12(2):170-3.

Zeller, M., Patton, J. T., Heylen, E., De Coster, S., Ciarlet, M., Van Ranst, M., Matthijnssens, J. 2012. Genetic analyses reveal differences in the VP7 and VP4 antigenic epitopes between human rotaviruses circulating in Belgium and rotaviruses in Rotarix and RotaTeq. Journal of clinical microbiology, 50(3), 966-976.

\section{How to cite this article:}

Mayara, A.O. Neves, Daniel S. De Camargo, Kathleen V.S. de Araújo, Patrícia S. Lobo, Renato Da S. Bandeira, Luana S. Soares and Joana D.P. Mascarenhas. 2018. Genomic Analysis of Rotavirus Species A Isolated from Swine, Amazon Region, Brazil. Int.J.Curr.Microbiol.App.Sci. 7(11): 792-814. doi: https://doi.org/10.20546/ijcmas.2018.711.095 